\title{
O contributo de Vilém Flusser para a ética na época da imaginação digital
}

Dirk Michael Hennrich'

https://orcid.org/0000-0001-9680-916X

I - Fundação para a Ciência e a Técnologia (FCT) Centro de Filosofia da Universidade de Lisboa (CFUL) Lisboa, Portugal

Resumo: O presente artigo pretende demonstrar, a partir da navegação e do naufrágio como metáforas para a existência humana e para o estado atual da civilização ocidental, como o pensamento de Vilém Flusser contribui para uma conduta ética na época da imaginação digital e das imagens técnicas. Flusser é um dos poucos teóricos da mídia e das tecnologias digitais que oferece, através de conceitos basilares, uma resposta digna à desventura destrutiva em que se encontra a humanidade não somente nas realidades e espaços virtuais.

Palavras-chave: Vilém Flusser; ética; naufrágio; computação; imaginação digital.

Abstract: Vilém Flusser's contribution e to ethics in the age of digital imagination - The present article aims to demonstrate, starting from navigation and shipwreck as metaphors for the human existence and the current state of western civilization, how the thinking of Vilém Flusser contributes to an ethical conduct in the age of digital imagination and technical images. Flusser is one of the few media and digital technologies theorists, who offers through basic concepts, a dignified answer to the destructive misadventure in which humanity finds itself, not only in virtual spaces and realities.

Keywords: Vilém Flusser; ethics; shipwreck; computing; digital imagination.

From the delirium of joy, we fell into profound despondency and grief (SAVIGNY, 1818, p. 135), 


\section{Navegação}

Num dos mais conhecidos livros de Vilém Flusser, encontramos como lema a frase scribere necesse est, vivere non est: escrever é necessário, viver não é (FLUSSER, 1992, p. 6). A frase original é diferente e provém do político e líder militar Gneu Pompeio Magno, que disse, nas palavras de Plutarco, em tradução para o latim: Navigare necesse, vivere non est necesse ${ }^{1}$. Flusser fez esta ligação não apenas para descrever o próprio destino intelectual ou a intenção principal de sua teoria da escrita, mas também devido à sua noção sobre a relação estreita entre navegar e escrever em todo o tempo passado e ainda mais no tempo atual da imaginação digital e das imagens técnicas. Flusser era, neste sentido, igualmente um escritor e um navegador, comparável não com o capitão, o comandante ou qualquer marinheiro, mas justamente com o navegador, que é, ao lado do capitão, a pessoa mais importante da tripulação, para guiar o navio entre a calmaria e a tempestade com a ajuda das estrelas e das constelações estelares. Seguindo esta analogia entre escrever e navegar na época da imaginação digital, é possível mostrar uma característica importante da sua filosofia: Flusser, consequentemente, evitava qualquer estilo acadêmico e científico, usando poucas citações e ainda menos notas de rodapé, contando estórias curtas e metafóricas, com a tentativa de atingir os mais diversos assuntos da atualidade e chegar o mais perto possível do indizível ou do incompreensível rumo da época das imagens técnicas, da zerodimensionalidade e de uma suposta pós-história. Este estilo filosófico é, de certo modo, nada estranho e desconhecido na história da filosofia, mas sim uma admissão integral do fato de que a linguagem e seus conceitos não crescem como plantas; os conceitos não são criações naturais, mas sim culturais. Por isto, é importante sublinhar que, quando se fala de conceitos, muitas vezes se esquece de que os conceitos não são produtos científicos, nem analíticos, e que não correspondem a alguma verdade fixa e bem definida, mas que são produtos poéticos, sendo assim todas as ciências decerto ficções poéticas (FLUSSER, 1966).

Aristoteles designava o humano como zõon logon echon, como uma forma de vida com linguagem, e apenas a tradução alterada do grego para o latim, como ressalta Heidegger na sua Carta sobre o Humanismo (HEIDEGGER, 1996, p. 322), transformou o zõon logon echon naquele animal rationale, em um animal com razão ou quando é relacionado com o presente tema e no contexto do pensamento de Flusser, em um animal que conta como se fosse um computador, o que é uma consideração central para toda a filosofia da imaginação digital e da época das imagens técnicas. Em relação a esta designação do humano e da sua suposta essência ou característica principal, do animal que fala e do animal que raciocina, é preciso mencionar mais duas definições, a primeira de Johan Huizinga, que escreveu sobre o homo ludens, e a segunda de Ernst Cassirer,

1 O primeiro capítulo de uma biografia sobre Fernão de Magalhães, escrito por Stefan Zweig e publicado em 1938, contém uma longa homenagem ao Infante Dom Henrique (O Navegador) e é intitulado com a frase Navegare necesse est. Esta é provavelmente a razão de citar Infante Dom Henrique como inspiração para o lema Scribere necesse est, vivere non est. Frei nach HEINRICH DEM SEEFAHRER na edição alemã Die Schrift. Hat Schreiben Zukunft? Frankfurt am Main: Fischer Taschenbuch Verlag, 1992. 
cujo pensamento se desdobra em torno da definição do humano como um animal simbólico. Ambas as definições se posicionam em contraste com a noção do humano como animal rationale, sendo Huizinga e Cassirer autores importantes para o pensamento de Flusser e cujas posições se encontram incluídas na ideia do jogo de linguagem (Sprachspiel) da filosofia tardia de Ludwig Wittgenstein.

Continuando então a pensar um pouco mais longe a frase sobre o ato de escrever, que se refere à navegação como uma necessidade essencial e mais importante do que a própria vida, não podemos deixar de lembrar que a navegação sempre foi e ainda é uma locomoção bastante arriscada e que muitos navegadores perderam a vida naufragando. Navegar é perigoso porque a vida no mar é uma vida sem chão (ein bodenloses Leben). O que pode ocorrer quando um navio naufraga é muito bem contado na estória da balsa de Medusa, amplamente conhecida por meio da pintura de Théodore Géricault. Essa estória é uma analogia surpreendente da época da imaginação digital e das imagens técnicas.

A Medusa, nome tenebroso para um navio, era uma fragata francesa que naufragou, em 1816, na costa da Africa a caminho de Senegal, sem a possibilidade de salvar toda a tripulação nos barcos de salva-vida. Aproximadamente 150 pessoas foram empilhadas à força numa balsa mal construída, que parcialmente afundou com o peso. Quando os barcos de salvavidas tentaram puxar a balsa para a costa, os cabos foram cortados, deixando-a à deriva, sem rumo, no mar aberto. O quadro de Géricault ajuda-nos a imaginar o que aconteceu, mas é necessário também imaginar (e isso seria importante para explicar os conceitos chaves do pensamento de Flusser) que a fragata é naufragada, que já muitas pessoas foram perdidas nas ondas e que a tripulação dos barcos salvavidas cortaram todas as cordas que seguravam a balsa devido ao medo de também se afogarem, também, em razão da ausência total de responsabilidade. A balsa é deixada para trás sem água e comida suficientes e, em consequência, transforma-se num autêntico inferno humano, onde o canibalismo e a covardia reinam.

Este cenário pode servir como metáfora muito diferente da Metafísica dos Costumes publicada por Immanuel Kant em 1785, três décadas antes do naufrágio da balsa. É também distinta de qualquer outra fundamentação sistemática da ética, porque é uma imagem que aponta a uma constelação de conceitos da situação ética da nossa atualidade. Estes conceitos, que a imagem $A$ Balsa de Medusa implicitamente desencadeia, não oferecem um centro ou uma identidade. Ao contrário, eles representam uma ética que já não consolida e nem delimita; é uma ética sem chão (bodenlos), uma ética sem pátria nomádica (heimatlos und nomadisch), uma ética naufragada e uma ética de um naufrágio que já não consola, que talvez transmite alguma esperança, mas que nos ensina sobretudo uma decadência com dignidade. 


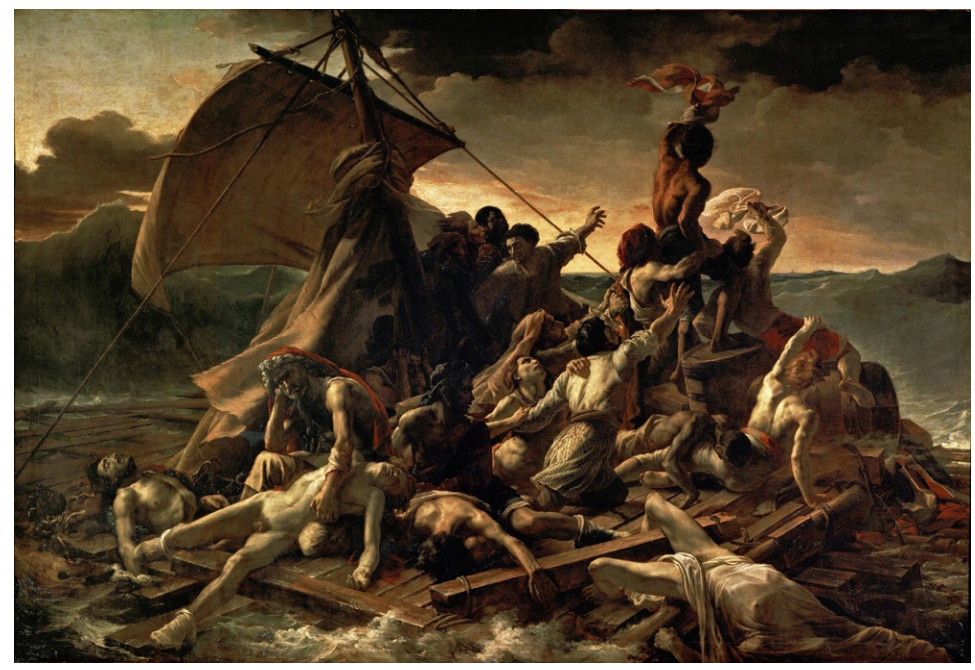

Fig. 1. A Balsa da Medusa, Théodore Géricault, 1819, Museu do Louvre, Paris.

A frase navigare necesse est, vivere non est necesse pode ser interpretada num sentido negativo e num sentido positivo. Em primeiro, atingindo apenas um ponto mais superficial, pode-se dizer que todos nós perdemos as nossas vidas navegando e que somos existências naufragadas, à deriva num mar repleto de objetos artificiais de diferentes tamanhos e que nós, como sujeitos orientados plenamente para estes objetos, tentamos nos segurar em algum deles durante o tempo máximo possível. O mar em que boiamos agarrados nestes objetos é sem chão, e todos que derivam nessa balsa se consideram sem pátria, apátridos ou desterrados (heimatlos) por entre o nada e sem esperança de regressar para casa, para o paraíso, os Campos Elísios, o lugar onde todos serão acolhidos, onde não haverá estranhamento e nem alienamento. Este mar em tormento, prestes a engolir todos os tripulantes da balsa, pode ser interpretado como o nosso planeta, a Terra, mas também como o nosso tempo civilizacional na época da imaginação digital e das imagens técnicas. Neste último caso, é possível imaginar que, no abismo do mar, vive um grande polvo que está prestes a engolir a balsa e toda a tripulação. Este polvo não é (apenas) o capitalismo, nem o comunismo ou qualquer outro ismo, mas algo diabólico no sentido etimológico da palavra. É algo que deveria unir todos com todos, porém, o que acontece é o oposto: o diabólico fragmenta e separa nós de nós mesmos e dos outros. Contudo, o pior é que este monstro, este Ungeheuer, é mesmo sinistro (unheimlich), porque é sem corpo e sem carne e apesar de tudo nos vicia. O diabólico aqui não significa diabólico no sentido da expressão para o caráter daquele que é chamado o diabo, mas o diabólico no sentido grego, como fragmentação, como $\delta 1 \alpha \beta \alpha \dot{\lambda} \lambda \varepsilon \varepsilon v$, o que corresponde efetivamente ao espírito do animal racional, porque contar, e ainda mais quando se refere à computação, 
é essencialmente fragmentação. O segundo sentido é que navegar é necessário em todos os tempos, porque sem navegar não tentamos o desconhecido, não tentamos o que se abre por trás do horizonte, quando estamos em pé ou sentado à beira-mar, no nosso espaço delimitado, no nosso chão, tendo uma casa, mas também sendo totalitário, tentando excluir o outro e os outros.

E agora atingimos o ponto de questionar como a filosofia de Flusser pode ser importante para pensar e repensar a nossa conduta ética e como ele introduz, com alguns conceitos da filosofia e da religião, o tempo atual e o futuro da imaginação digital. Nesta ética não conta mais a questão fundamental existencial que encontramos em pensadores do absurdo como Albert Camus, Porque eu não me mato?, porque na balsa boiando por cima do abismo seria e será necessário questionar: Como sobrevivo sem devorar meu próximo? A palavra devorar não se refere ao autêntico ingerir e digerir do outro, porque aqui se pretende diferenciar entre o Canibalismo e a Antropofagia como teoretizado por Oswaldo de Andrade e praticado por Flusser. Canibalismo é o que fazemos quando apenas reconsideramos a nossa fome e quando classificamos tudo e todos como um alimento para o nosso corpo. Antropofagia ao contrário é uma festa, um ritual sagrado, em que suspendemos o nosso eu para dar a honra aos outros, porque o outro é mais do que eu, porque o outro é a chave para nós mesmos, ressaltando aqui a diferença importante entre o eu e o selbst. É crucial aprender que não somos mais e não podemos ser mais sujeitos egocêntricos, nem objetos, e que nos percebemos, como Flusser tentou mostrar junto com Heidegger, que somos projetos, isto é, em vez de ser um eu ou um você, ser si mesmo, selbst. Já muito cedo, na sua obra Língua e Realidade, Flusser nos dá uma explicação lúcida da identidade do humano, definindo o selbst como um modo de relação e não como uma essência ou uma substância.

\section{Conceitos}

Os conceitos principais do pensamento de Flusser, que se inserem numa longa tradição filosófica, formam uma constelação capaz de traçar uma conduta ética, que pode servir para responder à desventura desastrosa em que se encontra, apesar de muitas vantagens e inovações importantes, a tecnologia digital e a sociedade mediática no seu conjunto, e ainda como característica e expressão máxima da cultura ocidental e dos seus avatares globalizados.

\section{Bodenlos}

O conceito principal do pensamento e da vida de Flusser é a palavra bodenlos, sem chão, e é justamente por esta razão o título da sua autobiografia. Na introdução do livro Bodenlos: uma autobiografia filosófica, encontramos a definição do termo absurdo, 
que Flusser interpreta como a experiência de uma existência sem chão, Bodenlosigkeit, no sentido de estar 'sem raízes' (FLUSSER, 1992, p. 9) Este conceito principal é assim diretamente ligado ao conceito Heimatlosigkeit, de não ter pátria, e do nomadismo, sendo o termo assim, como diria Heidegger, um existencial, uma disposição fundamental (Grundstimmung) de estar no mundo, paradoxalmente, sem estar com qualquer fundamento, sem ser fundado e enraizado no mundo. Por isso, o conceito precisa ser interpretado também num sentido heideggeriano, como Ab-Grund, o abismo, de que tudo parte e para onde tudo retorna.

\section{Aparato}

O próximo conceito, não necessariamente na ordem, mas muito importante para o presente excurso, é a caixa preta ou o aparato, como é interpretado por Flusser na sua Filosofia da Fotografia (FLUSSER, 1983, p. 20-30). O aparato não é uma ferramenta (Werkzeug), como, por exemplo, o martelo, que é nada menos do que uma prolongação do corpo e que não esconde o seu programa. O aparato ao contrário não desvela e oferece facilmente seu programa para o usuário, deconstruindo, em consequência, voluntariamente ou involuntariamente, qualquer relação simétrica. As caixas pretas que produzem imagens técnicas, como a máquina fotográfica ou a filmadora, ainda não imprimem seus programas no operador de tal forma como o computador e os dispositivos digitais mais recentes são capazes de programar seus usuários. Contudo, o aparato, que é uma caixa preta, não é uma máquina, não é somente um objeto técnico, mas também qualquer estrutura social (sistema político) e qualquer construção arquitetônica (presídios e campos de concentração) que transformam os humanos (e os não-humanos) em meros objetos ou, dito em palavras kantianas, em meios e não em fins. Por isso, Flusser, que fugiu do nazismo e cujos pais foram assassinados nos campos de concentração de Buchenwald e de Auschwitz, ressalta que apenas sobrevivemos com dignidade enquanto jogamos contra os mecanismos das caixas pretas, contra os programas que os aparatos técnicos, sociais e políticos pretendem inocular.

\section{Liberdade}

Neste ponto, encontramos mais dois conceitos importantes do pensamento de Flusser radicados na filosofia existencial e chamados engajamento e desengajamento, diretamente relacionados ao conceito da liberdade. No contexto da problemática que surge com os aparatos, com os dispositivos técnicos que produzem imagens ou que nos introduzem a uma assim chamada realidade virtual programada por eles, a liberdade se revela sempre como uma liberdade ilusória e relativa. Dentro das possibilidades oferecidas pelo respectivo programa, surge uma liberdade de escolha que cresce ou que diminui 
com a quantidade de escolha, sendo assim disponibilizada uma liberdade quantitativa, mas não uma liberdade qualitativa. Como também no contexto da ideologia do mercado, a liberdade se resolve apenas na escolha entre um e outro, entre um programa de televisão e o outro, ou entre um produto e o outro. De modo diferente aparece a liberdade qualitativa no pensamento de Flusser, exemplificada pela liberdade do migrante, daquele que não é mais um sedentário, mas que se lança numa existência nomádica, sem escolha de um solo/ chão, em alemão Boden, (pré-)determinado. O migrante vive sem pátria (ohne Heimat) e se desprende de todos os laços pré-estabelecidos para estabelecer laços e responsabilidades com os próximos que jamais são apenas os seus conterrâneos, parentes ou familiares. Esta liberdade corresponde com uma autêntica responsabilidade pelo próximo que não pode ser confundida com uma responsabilidade abstrata e humanista de ser responsável pela humanidade inteira, mas que é a liberdade de responsabilidade pelo próximo. Para Flusser, a pátria são aqueles para quem eu tenho escolhido a minha responsabilidade (FLUSSER, 1994, p. 26).

\section{Responsabilidade}

Responsabilidade é com certeza o mais importante conceito ético na obra de Flusser e que é diretamente ligado com o conceito da liberdade. Do ponto de vista rudimentar, todos nós temos a responsabilidade de nos engajar ou desengajar e deveríamos, quando percebemos que as caixas pretas se transformam em aparatos diabólicos ou até em certos tipos de campos de concentração, dar um passo para trás e desengajar-nos. O humano possui uma responsabilidade fundamental, que é a responsabilidade perante si mesmo. Todo humano tem, em primeiro, a sua própria e particular responsabilidade, isto é, todo humano precisa e deve libertar a si mesmo: todos nós precisamos aprender a andar e nadar sozinhos, sem a ajuda dos outros. Em escala universal, porém, a responsabilidade é um vetor normativo, que por si não se baseia numa ética específica e ainda menos numa certa religião, mas que é, antes de tudo, uma disposição originária do humano, por meio da qual todas as éticas universais se fundam. Somos acostumados a entender a responsabilidade no sentido moral ou religioso, escreve Heidegger, mas é preciso perceber a responsabilidade filosoficamente como modo excelente de replicar; e replicar é, essencialmente e propositadamente, a capacidade de responder (HEIDEGGER, 1998, p. 121). A responsabilidade, porém, nunca cessa e nunca é resolvida, pois se baseia na dinâmica propulsora da relação e do nexo ético entre o ato de questionar e o ato de responder. A capacidade da responsabilidade é a base do entendimento hermenêutico que deriva da possibilidade de o humano questionar o seu mundo em particular e o mundo em geral.

\section{Amor ao próximo.}

Outro termo central na obra de Flusser e do seu pensamento ético é o amor pelo próximo, em alemão Nächstenliebe. Amor ao próximo é, provavelmente, um conceito 
completamente disfuncional para a internet e as redes sociais, porque o conceito inclui o aspecto corporal e sensitivo, de ser tocado por alguém que se situa próximo de nós. Quando Flusser menciona Nächstenliebe, aparece junto a esse conceito o que é chamado Abstandslosigkeit, falta de distância, palavra que encontramos como conceito chave no pensamento de Heidegger. Abstandlosigkeit é, para Heidegger e no uso da língua alemã, um desrespeito, não ter distância perante o outro, invadir sem permissão o espaço privado do outro. Por isso e devido à peculiaridade das novas tecnologias, Nächstenliebe é para Flusser uma fusão entre a crítica nietzscheana do amor ao próximo no cristianismo e do conceito ou da ideia do amor ao mais distante, Fernstenliebe: amar o próximo em qualquer distância, recusando, ao mesmo tempo, a doutrina absurda do humanismo, de que deveríamos amar a humanidade inteira.

\section{Projecção}

A posição principal de Flusser era cética e ele queria que começássemos a duvidar profundamente da atitude eufórica perante as novas tecnologias digitais que revelam cada vez mais um caráter totalitário. A idade digital e eletrônica repete uma dinâmica mitológica e demiúrgica, criando um mundo sem ter cuidado, em qualquer momento, dos efeitos e ainda menos dos significados produzidos. Podemos afirmar que o Deus, o supremo criador e a causa de todos os bens, é realmente morto e substituído por um demiurgo que não quer saber do bem ou do mal, porque seu único objetivo é objetivar tudo e todos para fazer seus adeptos dependentes do seu programa (no sentido grego do

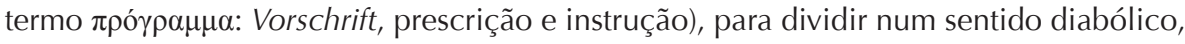
fazendo-nos crer que tudo é próximo, e que tudo e todos têm acesso aberto, bem como a habilidade e a liberdade de atingir os nossos mais secretos desejos. Mas, como podemos ver e perceber, o demiurgo não possui qualquer atitude ética ou ainda menos uma matriz ética, sendo, assim, vão pensar acerca de uma ética na época digital (e também nas nossas vidas fundadas na terra) enquanto permanecemos na diferença entre sujeito e objeto, enquanto as categorias metafísicas ainda permanecem em vigor.

É um desafio tentar explicar todas as implicações do pensamento ético de Flusser a partir dos conceitos acima mencionados, mas talvez é possível compreendê-los melhor se lembrarmos que o filósofo tentou transportar conceitos fenomenológicos, existencialistas e judaico-cristãos, todos pertencentes a certa noção de humano, a um entendimento bem específico e humanista aplicado a uma situação diferente e (u-tópica), no qual

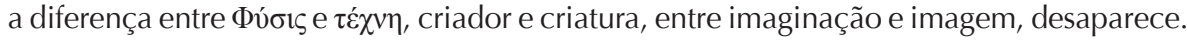
Esta existência não é mais uma existência que depende dos conceitos fundamentais da metafísica, como posto por Heidegger, Mundo, Finitude e Solidão, e que atingiremos apenas quando aprendermos a jogar contra a caixa preta; quando fugirmos do imenso campo de concentração que é regido pelo demiurgo e que é o próprio programa. 
Podemos afirmar, de outro modo, como antigamente, que as máquinas e a técnica, em geral, regem igualmente sobre os humanos e os não-humanos e que é necessário iniciar uma nova forma de vida com e perante as nossas invenções técnicas, pois nada mudará se apenas aperfeiçoamos os assim chamados aparatos.

Dirk Michael Hennrich é investigador de pós-doutoramento da Fundação para a Ciência e a Tecnologia (FCT) e membro integrado do Centro de Filosofia da Universidade de Lisboa (CFUL).

dh@letras.ulisboa.pt

\section{Referências}

FLUSSER, V. Bodenlos. Eine philosophische Biographie. Bensheim: Bollmann, 1992.

. Da Ficção, O Diário de Riberão Preto, 26/08/1966, Disponível em: http://www.flusserbrasil. com/art2.html Acesso em: 05/03/2019.

Die Schrift. Hat Schreiben Zukunft. Frankfurt am Main: Fischer Taschenbuch Verlag, 1992.

. Fur eine Philosophie der Fotografie. Gottingen: European Photography, 1983.

. Wohnung beziehen in der Heimatlosigkeit, In: Von der Freiheit des Migranten. Einspruche gegen den Nationalismus. Bensheim: Bollmann Verlag, 1994.

HEIDEGGER, M. Brief über den Humanismus, In: Wegmarken. Frankfurt am Main: Vittorio Klostermann, 3ª edição, 1996.

Die Logik als die Frage nach dem Wesen der Sprache. Obra Completa, Vol. 38, Frankfurt am Main: Vittorio Klostermann, 1998.

SAVIGNY, J. B. H. Narrarive of a Voyage to Senegal. London: 1818.

Texto recebido em 20/11/2018

e aprovado em 12/02/2019. 